\title{
Sexual health and HIV risk behaviors of men who have sex with men in Myanmar-Baseline findings from Link Up
}

Population Council

Burnet Institute

Follow this and additional works at: https://knowledgecommons.popcouncil.org/departments_sbsr-hiv

Part of the Demography, Population, and Ecology Commons, Family, Life Course, and Society Commons, Gender and Sexuality Commons, and the International Public Health Commons How does access to this work benefit you? Let us know!

\section{Recommended Citation}

Population Council and Burnet Institute. 2015. "Sexual health and HIV risk behaviors of men who have sex with men in Myanmar-Baseline findings from Link Up," Study brief. Washington, DC: Population Council. 


\section{SEXUAL HEALTH AND HIV RISK BEHAVIORS OF MEN WHO HAVE SEX WITH MEN IN MYANMAR- BASELINE FINDINGS FROM LINK UP}

In 2013, an estimated 189,000 people were living with HIV in Myanmar. ${ }^{1}$ The overall adult HIV prevalence is estimated to be around 0.5 percent, but key populations such as men who have sex with men (MSM) bear a disproportionate disease burden. ${ }^{2}$ There are an estimated 240,000 MSM in Myanmar, corresponding to 1.4 percent of the total adult male population. ${ }^{3}$ According to national estimates, HIV prevalence among MSM is 20 times higher than in the general population, at 10 percent. ${ }^{4}$ Though rarely enforced, Myanmar's penal code includes broad anti-sodomy laws that carry prison sentences of up to ten years. ${ }^{5}$

Effective, targeted, innovative, and culturally appropriate interventions that have been shown to significantly reduce high-risk sexual behaviors among MSM are needed to reduce the HIV burden among this population. In Myanmar, as part of the Link Up project-a global consortium led by the International HIV/AIDS Alliance-Alliance Myanmar and Marie Stopes InternationalMyanmar (MSI-M) will carry out a project in which MSM peer educators from local community-based organizations (CBOs) will provide face-to-face peer education on sexual health and HIV issues, including referrals to local Link Up health facilities for services such as HIV testing and counseling and condom provision.

The Population Council, in collaboration with the Burnet Institute, is conducting an evaluation of these Link Up activities in Myanmar. This brief describes findings from the baseline data collection activities among MSM in Link Up sites. sites (three intervention and three comparison sites), a total of 623 MSM were recruited via respondent driven sampling, a peer-

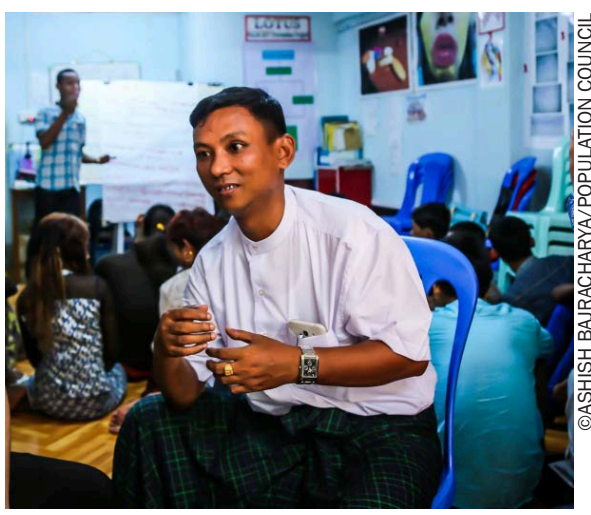

At the LOTUS center in Yangon, young peer educators counsel young MSM on sexual health and HIV and STI risks as a part of Link Up's peer education activities.

\section{KEY MESSAGES}

MSM use condoms relatively consistently, but need additional awareness of and access to latex-safe lubricant.

Efforts to increase HIV testing among MSM should focus on reducing fears associated with learning one's status, and facilitating linkages to HIV testing services.

Program planners and policy makers must understand the diversity of sexual identities of MSM, such as bisexual and "hidden" MSM. 
recruitment sampling method that allows researchers to gain access to hidden populations through their social networks. Eligible participants were young MSM, aged 18 to 24 years. For the purposes of this research, MSM was defined as any male who has had sexual intercourse with another male in the past six months. Trained research interviewers who were recruited from the MSM community administered structured questionnaires to collect data on participant demographics, previous contact with MSM peer outreach programs, knowledge of HIV and sexually transmitted infections (STIs), prevention knowledge and practices, and experiences and perceptions of stigma and discrimination within the health services.

\section{STUDY POPULATION}

The mean age of participants was 20.4 years, 77 percent of participants had completed at least middle or high school and 83 percent were currently employed. Over 80 percent of participants were never married and nearly 10 percent were committed to a man as married. Very few ( 2 percent) had children.

\section{KEY FINDINGS}

\section{Sexual history}

The mean age of sexual debut with a male partner among study participants was just over 16 , and a notable proportion (15 percent) reported being coerced into their first sexual experience. More than half of the participants (54 percent) identified as "than-ge," which is a hidden MSM who takes on the insertive role in a sexual relationship, 16 percent identified as "apone" (a hidden MSM who is normally in the receptive role), and one-third identified as "apwint," (a non-hidden MSM who also takes on the receptive role). Ninety-two percent reported having had sexual intercourse in the previous 90 days. Of these, nearly three-quarters had only had sex with men, 6 percent only with women, and 20 percent had had sex with both men and women (Figure 1).

\section{Condom use}

Condom use at last anal sex was higher with casual male partners compared to regular male partners. It was, however, still over 70 percent with regular male partners. In terms of consistency of condom use in the past 30 days (defined as "always" using condoms), 78 percent responded that they always used condoms with casual and paying male partners. This was slightly lower (63 percent) with regular male partners (Figure 2). Of the 126 participants who had had vaginal sex with females, 60 percent used a condom at last intercourse. Fifteen of the twenty MSM who said that they had had anal sex with females reported using a condom at last anal sex (data not shown). Most participants stated they were confident to obtain condoms and to suggest their use with new sexual partners. When asked about reasons for not using condoms, the most common response for all partner types was that participants trusted their partners.

\section{Lubricant knowledge and use}

When asked whether there is a particular type of lubricant that should be used with latex condoms, 56 percent responded affirmatively. When these participants were asked to specify the types of lubricants that should be used, the most frequently indicated products were "Vaseline or other petroleum jelly products" (98 percent) and "Aphaw gel, IDA, KY Jelly or other water-based products" (97 percent). However, when asked about actual use of lubricants, water-based products were by far the most popular options. With regular male partners, 63 percent reported that they used lubricant the last time they

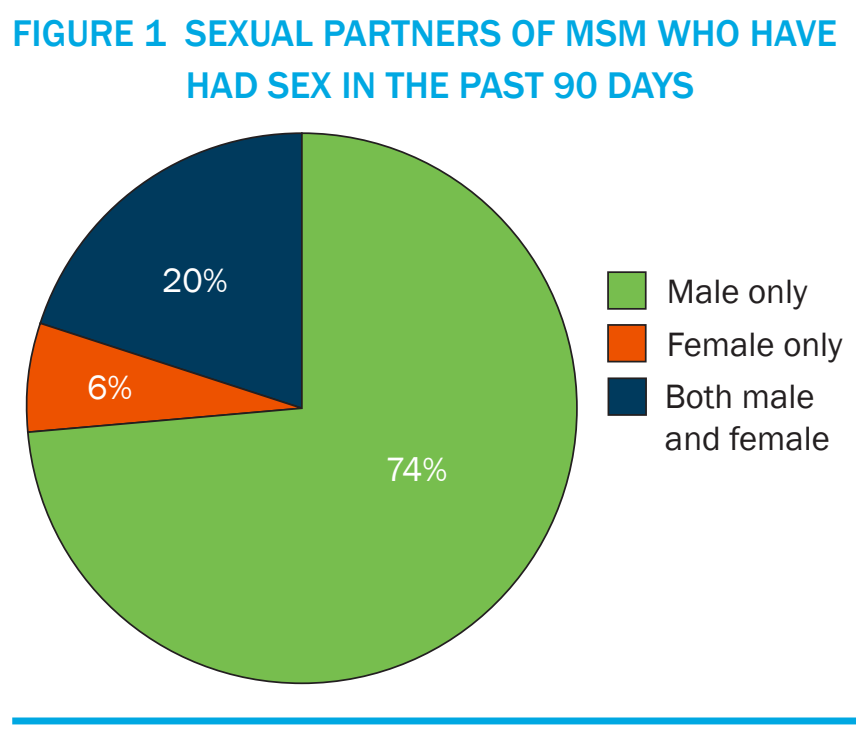


FIGURE 2 CONSISTENT CONDOM USE WITH

DIFFERENT MALE PARTNERS IN THE

PAST 30 DAYS

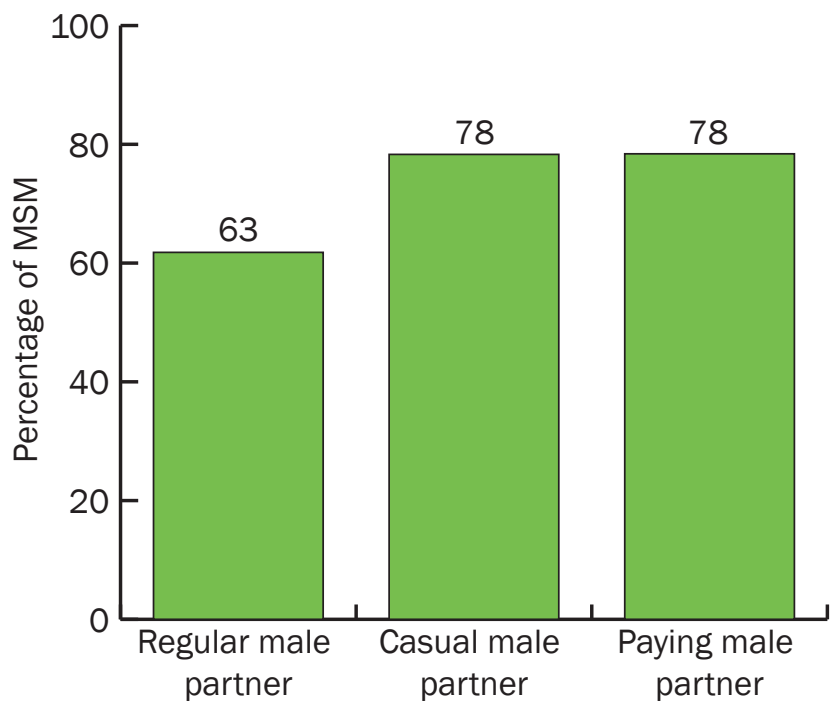

had sex, with 99 percent reporting that they used a water-based lubricant. Similarly, among those who had non-regular male partners, 47 percent used a lubricant the last time they had sex, among whom 91 percent used a water-based lubricant.

\section{Knowledge about HIV}

More than 90 percent of participants knew that they could acquire HIV from having unprotected anal sex and from using unclean injecting equipment. Participants were less likely to agree that you could protect yourself from HIV by abstaining from sex (59 percent), and only three-quarters of participants agreed that you could protect yourself from HIV by having only one uninfected faithful sexual partner. One-third believed that HIV could be transmitted through mosquito bites. Two-thirds of all participants knew someone with HIV and AIDS, and more than 85 percent of all participants knew that there was medication available for HIV-positive people. A majority (76 percent) of participants knew that it was possible to get a confidential HIV test in their community.

\section{HIV testing}

Two-thirds of participants had ever received counseling or testing for HIV. The majority of participants who had tested had done so in the previous 12 months, and nearly all of them had received their test result. Among the 355 tested men who were willing to share their results, 8 percent reported they were HIVpositive (Table 1). Among these positive participants, 46 percent were receiving antiretroviral therapy.

The largest proportion of participants (53 percent) received testing at the PSI Targeted Outreach Project (TOP) centers. MSI-M clinics were attended by 16 percent of participants (Table 1 ). When asked about barriers to testing, the most common responses included trusting themselves, feeling healthy, and afraid of learning their status.

\section{Stigma, discrimination and violence}

Approximately one quarter of all participants had been verbally insulted because they were MSM.

Fifteen percent of participants reported that they had been forced to have sex, or that they had been sexually assaulted because they were MSM. Five percent

\section{TABLE 1 HIV TESTING HISTORY}

\begin{tabular}{lc}
\hline Variable & $\%(\mathrm{n})$ \\
\hline Ever received HIV test $(\mathrm{n}=623)$ & $63.7(397)$ \\
When was your most recent HIV test? $(\mathrm{n}=397)^{*}$ & \\
$\quad<3$ months ago & $56.2(223)$ \\
3-6 months ago & $19.7(78)$ \\
6-12 months ago & $11.6(46)$ \\
>12 months ago & $11.3(45)$ \\
Do not remember & $1.0(4)$ \\
Received results of most recent HIV test $(\mathrm{n}=400)^{* *}$ & $97.0(388)$ \\
Result of most recent test $(\mathrm{n}=355)^{* * *}$ & \\
Positive & $7.6(27)$ \\
Negative & $91.6(325)$ \\
Indeterminate & $0.9(3)$ \\
Place of last HIV test $(\mathrm{n}=411)$ & \\
Government hospital & $11.7(48)$ \\
National AIDS programme & $1.2(5)$ \\
MSI-M clinic & $16.8(69)$ \\
PSI TOP & $53.3(219)$ \\
Private clinic & $6.3(26)$ \\
International NGO & $1.7(7)$ \\
CBO/self-help group & $8.0(33)$ \\
Other & $1.0(4)$ \\
\hline
\end{tabular}

"One participant gave "no answer"

**Three participants answered "don't know"

${ }^{* * *}$ Among those willing to share test result 
had been hit, kicked, or beaten on account of their sexual preferences, and 2 percent had been refused health care services.

\section{PROGRAM IMPLICATIONS AND RECOMMENDATIONS}

This baseline assessment yields some noteworthy findings that highlight critical HIV knowledge gaps among Myanmar MSM, as well as the need to increase preventive behaviors such as condom use and HIV testing and counseling. Although condom use is very high, these findings underscore the need for education about the importance of using latex-safe lubricant. Furthermore, with a substantial proportion reporting having female partners or living as "hidden" MSM, outreach efforts to these communities must be innovative and confidential, with providers highly sensitized to the unique needs of this population.

Among those who had been tested and were willing to disclose their test results, the self-reported HIV prevalence in this study population was on par with recent national surveillance data among Myanmar MSM-more than ten times higher than the general adult prevalence in the country. Given that more than one-third had never been tested, there is a need to raise awareness about the importance and availability of HIV testing services in the community. By deploying peer outreach workers and sensitizing facility providers on how to provide MSM-friendly care, the Link Up project aims to improve these men's access to health information as well as respectful HIV and sexual health services.

\section{REFERENCES}

${ }^{1}$ Strategic Information and Monitoring and Evaluation Working Group: Technical and Strategy Group on AIDS. 2011. HIV Estimates and Projections: Asian Epidemiological Model. Myanmar 2010-2015. Yangon: National AIDS Programme.

${ }^{2}$ National AIDS Programme. 2012a. Global AIDS Response Progress Report. Yangon: National AIDS Programme.

${ }^{3}$ National AIDS Programme. 2012b. Results of HIV Sentinel Sero-surveillance 2011. Yangon: National AIDS Programme.

${ }^{4}$ National AIDS Programme. 2013. Result of HIV Sentinel Sero-surveillance 2012. Yangon: National AIDS Programme.

${ }^{5}$ Myanmar Penal Code: Ch. XVI, § 377.

Link Up aims to improve the sexual and reproductive health and rights (SRHR) of one million young people affected by HIV across five countries in Africa and Asia. The project is being implemented by a consortium of partners led by the International HIV/AIDS Alliance.

Link Up consortium partners

- ATHENA Network

- Global Youth Coalition on HIV/AIDS

- International HIV/AIDS Alliance

- Marie Stopes International in Bangladesh, Myanmar and Uganda

- Population Council

Other key collaborators include UNFPA, UNESCO and AIDS Fonds. Funded by the Ministry of Foreign Affairs of the government of the Netherlands (BUZA).

To follow the progress of Link Up, visit www.link-up.org
- STOP AIDS NOW!

- Alliance Burundaise Contre le SIDA in Burundi

- Organisation for Support Services for AIDS (OSSA) in Ethiopia

- Alliance Myanmar

- Community Health Alliance Uganda
POPULATION COUNCIL

Ideas. Evidence. Impact.
The Population Council confronts critical health and development issues-from stopping the spread of HIV to improving reproductive health and ensuring that young people lead full and productive lives. Through biomedical, social science and public health research in about 50 countries, the Council works with our partners to deliver solutions that lead to more effective policies, programs, and technologies to improve lives worldwide. Established in 1952 and headquartered in New York, the Council is a nongovernmental, nonprofit organization with an international board of trustees.

Suggested citation: Population Council and Burnet Institute. 2015. "Sexual health and HIV risk behaviors of men who have sex with men in MyanmarBaseline findings from Link Up," Link Up Study Brief. Washington, DC: Population Council. 